\title{
EFFECT OF SECOND SOUND ON THE ONSET OF RAYLEIGH- BENARD CONVECTION IN A MICROPOLAR FLUID
}

\author{
S. Pranesh*
}

\begin{abstract}
The effects resulting from the substitution of the classical Fourier low by the non-classical Maxwell-Cattaneo low in Rayleigh-Benard convection in micropolar fluid is studied. The classical approach predicts an infinite speed for the propagation of heat. The present non-classical theory involves a wave type heat transport (SECOND SOUND) and does not suffer from the physically unacceptable drawback of infinite heat propagation speed. It is found that the results are noteworthy at short times and the critical eigenvalues are less than the classical ones.
\end{abstract}

\section{Introduction}

Convection in fluid suspensions has been the subject of intensive study because of the remarkable physical properties of the fluid as well as its practical applications (see Power 1995, Lukaszewicz 1998, Eringen 1999). Rayleigh-Benard convection

* Head, P.G. : Department of Mathematics, Christ College (Autonomous), Hosur Road, Bangalore560029 , INDIA 
in fluids with suspended particles have been studied by a number of authors (120). The reported works on convection concern fluid suspensions with classical Fourier heat flux law.

The drawback of the classical law motivated Lindsay and Stranghan (1978), Stranghan and Franchi (1984), Lebon and Cloot (1984) and Siddheshwar (1993, 1999) to adopt a non-classical heat flux law in studying Rayleigh - Benard / Marangoni convection. The hyperbolic heat equation (SECOND SOUND) model adopted by these authors does not suffer from the physically unacceptable drawback of infinite heat propagation speed. The principle of exchange of stability is also not guaranteed in these problems.

The objective of this chapter is to replace the classical parabolic heat equations by non-classical Maxwell-Cattaneo heat flux law and study Rayleigh-Benard convection in micropolar fluids.

\section{Mathematical Formulation}

Consider an infinite horizontal layer of a Boussinesquian, Micropolar fluid of depth d. A cartesian co-ordinate system is taken with origin in the lower boundary and zaxis vertically upwards. Let $\Delta T$ be the temperature difference between the upper and lower boundaries. The body force acting on the fluid is buoyancy.

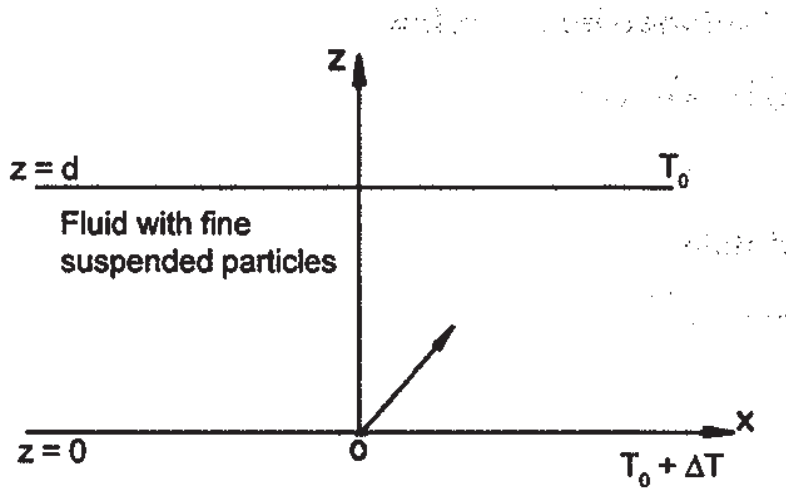

Fig 1 : Schematic Diagram of the Rayleigh-Benard Situation for a Fluid with Suspended Particles 
The governing equations for the Rayleigh-Benard situation in a Boussinesquian Micropolar fluid are:

Continuity equation

$\nabla \cdot \vec{q}=0$

\section{Conservation of linear momentum}

$\rho_{0}\left[\frac{\partial \overrightarrow{\mathrm{q}}}{\partial \mathrm{t}}+(\overrightarrow{\mathrm{q}} \cdot \nabla) \overrightarrow{\mathrm{q}}\right]=-\nabla \mathrm{P}-\rho \mathrm{g} \hat{\mathrm{k}}+(2 \zeta+\eta) \nabla^{2} \overrightarrow{\mathrm{q}}+\zeta \nabla \times \overrightarrow{\mathrm{w}}$,

\section{Conservation of angular momentum}

$\rho_{0} \mathrm{I}\left[\frac{\partial \vec{\omega}}{\partial \mathrm{t}}+(\overrightarrow{\mathrm{q}} \cdot \nabla) \vec{\omega}\right]=\left(\lambda^{\prime}+\eta^{\prime}\right) \nabla(\nabla: \vec{\omega})+\eta^{\prime} \nabla^{2} \vec{\omega}+\zeta(\nabla \times \overrightarrow{\mathrm{q}}+2 \vec{\omega})$

Conservation of energy

$$
\frac{\partial \mathrm{T}}{\partial \mathrm{t}}+\left(\overrightarrow{\mathrm{q}}-\frac{\beta}{\rho_{\mathrm{o}} \mathrm{C}_{\mathrm{V}}} \nabla \times \vec{\omega}\right) \cdot \nabla \mathrm{T}=\frac{\nabla \cdot \overrightarrow{\mathrm{Q}}}{\rho_{0} \mathrm{C}_{\mathrm{v}}},
$$

\section{Maxwell - Cattaneo heat flux law}

$$
\tau\left[\dot{\overrightarrow{\mathrm{Q}}}+\vec{\omega}_{1} \times \overrightarrow{\mathrm{Q}}\right]=-\overrightarrow{\mathrm{Q}}-\kappa \nabla \mathrm{T},
$$

\section{Equation of state}

$\rho=\rho_{o}\left[1-\alpha\left(T-T_{0}\right)\right]$,

where

$\vec{\omega}_{1}=\frac{1}{2} \nabla \times \vec{q}, \vec{Q}$ is the heat flux vector and $\tau$ is the constant relaxation time. 
The aim of this paper is to investigate the stability of a quiescent state to infinitesimal perturbations superposed on the basic state. The basic state of the fluid being quiescent is described by

$$
\overrightarrow{\mathrm{q}}_{\mathrm{b}}=0, \vec{\omega}_{\mathrm{b}}=0, \mathrm{p}=\mathrm{p}_{\mathrm{b}}(\mathrm{z}), \rho=\rho_{\mathrm{b}}(\mathrm{z}), \mathrm{T}=\mathrm{T}_{\mathrm{b}}(\mathrm{z}), \overrightarrow{\mathrm{Q}}=\left(0,0, \mathrm{Q}_{\mathrm{b}}(\mathrm{z})\right)
$$

Equations (2), (4) and (6) in the basic state specified by equation (7) respectively become

$$
\begin{aligned}
& \frac{d P_{b}}{d z}=-\rho_{0} g, \\
& \frac{d^{2} T_{b}}{d z^{2}}=0, \\
& \rho_{b}=\rho_{0}\left[1-\alpha\left(T_{b}-T_{0}\right)\right], \\
& Q_{b}=-\kappa \frac{d T_{b}}{d z}
\end{aligned}
$$

Equations (1), (3) and (5) are identically satisfied by the concerned basic state variables. We now superpose infinitesimal perturbations on the quiescent basic state and study the stability.

\subsection{Linear Stability Analysis}

Let the basic state be disturbed by an infinitesimal thermal perturbation. We now have

$$
\left.\begin{array}{lll}
\vec{q}=\vec{q}_{b}+\vec{q}^{\prime}, & \vec{\omega}=\vec{\omega}_{b}+\vec{\omega}^{\prime}, & p=p_{b}+p^{\prime}, \\
\rho=\rho_{b}+\rho^{\prime}, & T=T_{b}+T^{\prime}, & \vec{Q}=\vec{Q}_{b}+\vec{Q}^{\prime}
\end{array}\right\}
$$

The primes indicate that the quantities are infinitesimal perturbations and subscript $b$ indicates basic state value. 
Substituting equation (9) into equations (1)-(6) and using the basic state (8), we get the linearised equations governing the infinitesimal perturbations in the form:

$\nabla \cdot \vec{q}^{\prime}=0$,

$\rho_{o} \frac{\partial \overrightarrow{\mathrm{q}}^{\prime}}{\partial \mathrm{t}}=-\nabla \mathrm{p}^{\prime}-\rho^{\prime} \mathrm{g} \hat{\mathrm{k}}+(2 \zeta+\eta) \nabla^{2} \overrightarrow{\mathrm{q}}^{\prime}+\zeta \nabla \times \vec{\omega}^{\prime}$

$\rho_{0} \mathrm{I} \frac{\partial \vec{\omega}}{\partial \mathrm{t}}=\left(\lambda^{\prime}+\eta^{\prime}\right) \nabla\left(\nabla . \vec{\omega}^{\prime}\right)+\eta^{\prime} \nabla^{2} \vec{\omega}^{\prime}+\zeta\left(\nabla \times \overrightarrow{\mathrm{q}}^{\prime}-2 \vec{\omega}^{\prime}\right)^{\prime}$

$\frac{\partial \mathrm{T}^{\prime}}{\partial \mathrm{t}}=\frac{\Delta \mathrm{T}}{\mathrm{d}}\left(\frac{\beta}{\rho_{0} \mathrm{C}_{\mathrm{v}}} \nabla \times \vec{\omega}^{\prime} \cdot \hat{\mathrm{k}}-\mathrm{W}\right)-\frac{\nabla \cdot \overrightarrow{\mathrm{Q}}^{\prime}}{\rho_{0} \mathrm{C}_{\mathrm{v}}}$

$\left(1+\tau \frac{\partial}{\partial \mathrm{t}}\right) \overrightarrow{\mathrm{Q}}^{\prime}=-\frac{1}{2} \chi_{1} \frac{\Delta \mathrm{T}}{\mathrm{d}}\left(\frac{\partial \overrightarrow{\mathrm{q}}^{\prime}}{\partial \mathrm{z}}-\nabla \mathrm{W}^{\prime}\right)-\chi \nabla \mathrm{T}$,

$\rho^{\prime}=-\alpha \rho_{0} T^{\prime}$

Operating divergence on the equation (14) and substituting in equation (13), on using equation (10), we get

$$
\left.\begin{array}{r}
\left(1+\tau \frac{\partial}{\partial \mathrm{t}}\right) \frac{\partial \mathrm{T}^{\prime}}{\partial \mathrm{t}^{\prime}}=\left(1+\tau \frac{\partial}{\partial \mathrm{t}}\right) \frac{\Delta \mathrm{T}}{\mathrm{d}}\left[\frac{\beta}{\rho_{\mathrm{o}} \mathrm{C}_{\mathrm{v}}} \nabla \times \vec{\omega}^{\prime} \hat{\mathrm{k}}-\mathrm{W}^{\prime}\right] \\
-\frac{1}{2} \chi_{1} \frac{\Delta \mathrm{T}}{\mathrm{d}} \nabla^{2} \mathrm{~W}^{\prime}+\chi \nabla^{2} \mathrm{~T}^{\prime}
\end{array}\right\},
$$

The perturbation equations (11)-(12) and equation (16) are non-dimensionalised using the following definition:

$$
\left(\mathrm{x}^{*}, \mathrm{y}^{*}, \mathrm{z}^{*}\right)=\frac{(\mathrm{x}, \mathrm{y}, \mathrm{z})}{\mathrm{d}}, \overrightarrow{\mathrm{q}}^{*}=\frac{\overrightarrow{\mathrm{q}}^{\prime}}{\chi / \mathrm{d}}, \vec{\omega}^{*}=\frac{\vec{\omega}^{\prime}}{\chi / \mathrm{d}^{2}}, \mathrm{t}^{*}=\frac{\mathrm{t}}{\mathrm{d}^{2} / \chi}, \mathrm{T}^{*}=\frac{\mathrm{T}^{\prime}}{\Delta \mathrm{T}}
$$


Using equation (15) in equation (11), operating curl twice on the resulting equation, operating curl on equation (12) and non-dimensionalising the two resulting equations and also equation (16), we get

$$
\begin{aligned}
& \frac{1}{\operatorname{Pr}} \frac{\partial}{\partial t}\left(\nabla^{2} \mathrm{~W}\right)=\left(1+\mathrm{N}_{1}\right) \nabla^{4} \mathrm{~W}+\mathrm{N}_{1} \nabla^{2} \Omega_{\mathrm{Z}}+\mathrm{R} \nabla_{\mathrm{l}}^{2} \mathrm{~T} \\
& \frac{\mathrm{N}_{2}}{\operatorname{Pr}} \frac{\partial \Omega_{\mathrm{Z}}}{\partial \mathrm{t}}=\mathrm{N}_{3} \nabla^{2} \Omega_{\mathrm{z}}-2 \mathrm{~N}_{1} \Omega_{\mathrm{Z}}-\mathrm{N}_{1} \nabla^{2} \mathrm{~W} \\
& \left(1+\mathrm{C} \frac{\partial}{\partial \mathrm{t}}\right) \frac{\partial \mathrm{T}}{\partial \mathrm{t}}=\left(1+\mathrm{C} \frac{\partial}{\partial \mathrm{t}}\right) \mathrm{W}-\left(1+\mathrm{C} \frac{\partial}{\partial \mathrm{t}}\right) \mathrm{N}_{5} \Omega_{\mathrm{z}}+\nabla^{2} \mathrm{~T}-\mathrm{C} \nabla^{2} \mathrm{~W},
\end{aligned}
$$

where the asterisks have been dropped for simplicity and the non-dimensional parameters $N_{1}, N_{3}, N_{5}, R$ and $C$ are as defined as

$$
\mathrm{N}_{1}=\frac{\zeta}{\zeta+\eta} \quad \text { (Coupling Parameter) }
$$

$$
\mathrm{N}_{3}=\frac{\eta^{\prime}}{(\zeta+\eta) \mathrm{d}^{2}} \quad \text { (Couple Stress Parameter) }
$$

$$
\mathrm{N}_{5}=\frac{\beta}{\rho_{0} \mathrm{C}_{\mathrm{v}} \mathrm{d}^{2}} \quad \text { (Micropolar Heat Conduction Parameter), }
$$

$$
\operatorname{Pr}=\frac{\zeta+\eta}{\chi} \quad \text { (Prandtl number) }
$$

$$
\begin{array}{ll}
\mathrm{Pm}=\frac{\zeta+\eta}{\gamma_{\mathrm{m}}} & \text { (Magnetic Prandtl numb } \\
\mathrm{R}=\frac{\alpha \mathrm{g} \Delta \mathrm{Td}^{3} \rho_{0}}{(\zeta+\eta) \chi} & \text { (Rayleigh number) and }
\end{array}
$$


$\mathrm{C}=\frac{\tau \chi}{2 \mathrm{~d}^{2}}$

(Cattaneo number).

Equations (18) - (20) are solved for velocity stress free, isothermal and vanishing spin boundaries and hence the assumed boundary conditions are

$$
W=\frac{\partial^{2} W}{\partial z^{2}}=T=\Omega_{z}=0 \text { at } z=0,1
$$

The infinitesimal perturbations $W, \Omega_{z}$ and $T$ are assumed to be periodic waves (see Chandrasekhar 1961) and hence these permit a normal mode solution in the form

$$
\left[\begin{array}{c}
W \\
\Omega_{z} \\
T
\end{array}\right]=\left[\begin{array}{c}
W(z) \\
G(z) \\
T(z)
\end{array}\right] \exp [\sigma t+i(1 x+m y)]
$$

where $l$ and $m$ are horizontal components of the wave number $\vec{a}$.

Substituting equation (22) into equations (18) - (20), we get

$\frac{\sigma}{\operatorname{Pr}}\left(D^{2}-a^{2}\right) W=\left(1+N_{1}\right)\left(D^{2}-a^{2}\right)^{2} W-R a^{2} T+N_{1}\left(D^{2}-a^{2}\right) G$

$\frac{N_{2} \sigma G}{P r}=-N_{1}\left(D^{2}-a^{2}\right) W+N_{3}\left(D^{2}-a^{2}\right) G-2 N_{1} G$

$(1+2 C \sigma) \sigma \mathrm{T}=(1+2 \mathrm{C} \sigma) \mathrm{W}-(1+2 \mathrm{C} \sigma) \mathrm{N}_{5} \mathrm{G}+\left(\mathrm{D}^{2}-\mathrm{a}^{2}\right) \mathrm{T}-\mathrm{C}\left(\mathrm{D}^{2}-\mathrm{a}^{2}\right) \mathrm{W}$

where $\mathrm{D}=\frac{\mathrm{d}}{\mathrm{dz}}$. 
Eliminating $G$ and $T$ between the equations (23) - (25), we get a single equation involving $W$ in the form

$$
\left[\mathrm{Y}_{2} \mathrm{Y}_{3}+\mathrm{N}_{1}^{2}\left(\mathrm{D}^{2}-\mathrm{a}^{2}\right)\right] \mathrm{Y}_{1}\left(\mathrm{D}^{2}-\mathrm{a}^{2}\right) \mathrm{W}=-\mathrm{Ra} \mathrm{a}^{2}\left[\mathrm{Y}_{2} \mathrm{Y}_{4}+(1+2 \mathrm{C} \sigma)\left(\mathrm{D}^{2}-\mathrm{a}^{2}\right)^{2}\right] \mathrm{W}
$$

where

$Y_{1}=\sigma+2 C \sigma^{2}-\left(D^{2}-a^{2}\right)$

$Y_{2}=\frac{N_{2} \sigma}{\operatorname{Pr}}-N_{3}\left(D^{2}-a^{2}\right)+2 N_{l}$

$\mathrm{Y}_{3}=\frac{\sigma}{\operatorname{Pr}}-\left(1+\mathrm{N}_{1}\right)\left(\mathrm{D}^{2}-\mathrm{a}^{2}\right)$

and

$\mathrm{Y}_{4}=1+2 \mathrm{C} \sigma-\mathrm{C}\left(\mathrm{D}^{2}-\mathrm{a}^{2}\right)$

The solution for $W$ for the lowest mode is; as per Chandrasekhar (196i), taken in the form

$$
\mathrm{W}=\mathrm{A}_{0} \sin (\pi \mathrm{z})
$$

where $A_{0}$ is a constant. Substituting equation (27) in equation (26), we get

$$
\left.\begin{array}{r}
\left.\left(\mathrm{k}^{2}+2 \mathrm{C} \sigma^{2}+\sigma\right)\left[\left(\frac{\mathrm{N}_{2} \sigma}{\mathrm{Pr}}+\mathrm{N}_{3} \mathrm{k}^{2}+2 \mathrm{~N}_{1}\right)\left(\frac{\sigma}{\mathrm{Pr}}+\left(1+\mathrm{N}_{1}\right) \mathrm{k}^{2}\right)-\mathrm{N}_{1}^{2} \mathrm{k}^{2}\right] \mathrm{k}^{2}\right] \\
=\mathrm{Ra}^{2}\left[\left(\mathrm{~N}_{3} \mathrm{k}^{2}+2 \mathrm{~N}_{1}+\frac{\mathrm{N}_{2} \sigma}{\mathrm{Pr}}\right)\left(1+2 \mathrm{C} \sigma+\mathrm{Ck}^{2}\right)-(1+2 \mathrm{C} \sigma) \mathrm{N}_{1} \mathrm{~N}_{5} \mathrm{k}^{2}\right]
\end{array}\right\} ;
$$

where $\mathrm{k}^{2}=\pi^{2}+\mathrm{a}^{2}$. 


\subsection{Marginal State}

If $\sigma$ is real, then marginal stability occurs when $\sigma=0$. This gives the stationary Rayleigh number $R_{s}$ in the form

$$
R_{S}=\frac{\left(1+N_{L}\right) N_{3} k^{8}+N_{1}\left(2+N_{1}\right) k^{6}}{a^{2}\left[\left(1+C k^{2}\right)\left(N_{3} k^{2}+2 N_{1}\right)-N_{1} N_{5} k^{2}\right]}
$$

If $C=0$, the equation (29) reduces to

$$
R_{S}=\frac{k^{6}}{a^{2}}\left[\frac{\left(1+N_{1}\right) N_{3} k^{2}+2 N_{1}+N_{l}^{2}}{\left(N_{3}-N_{1} N_{5}\right) k^{2}+2 N_{1}}\right]
$$

which is the expression for the Rayleigh number discussed by Datta and Sastry (1976) and Bhattacharyo and Jena (1983).

\subsection{Oscillatory Motions}

To study the oscillatory motions we put $\sigma=i \omega, \omega \in \Re$, in equation (28). By equating the real and imaginary parts, the following equations are obtained

$$
R_{0}=\frac{\left\{T_{3}\left[T_{5} T_{1}-\omega^{2} T_{2}\right]+\omega^{2} k^{2} T_{4}\left[T_{1}+T_{5} T_{2}\right]\right\} k^{2}}{a^{2}\left\{T_{3}^{2}+\omega^{2} T_{4}^{2}\right\}}
$$

$$
A \omega^{4}+B \omega^{2}+E=0
$$

where

$$
\begin{aligned}
& \mathrm{T}_{1}=\mathrm{X}_{1}-\frac{\omega^{2} \mathrm{~N}_{2}}{\mathrm{Pr}^{2}}, \\
& \mathrm{~T}_{2}=\frac{\mathrm{N}_{3} \mathrm{k}^{2}+2 \mathrm{~N}_{1}+\left(1+\mathrm{N}_{1}\right) \mathrm{N}_{2} \mathrm{k}^{2}}{\operatorname{Pr}}, \\
& \mathrm{T}_{3}=\mathrm{X}_{2}-\frac{2 \mathrm{CN}_{2} \omega^{2}}{\operatorname{Pr}},
\end{aligned}
$$




$$
\begin{aligned}
& \mathrm{T}_{4}=2 \mathrm{C}\left(\mathrm{N}_{3} \mathrm{k}^{2}+2 \mathrm{~N}_{1}\right)+\frac{\mathrm{N}_{2}\left(1+\mathrm{Ck}^{2}\right)}{\operatorname{Pr}}-2 \mathrm{CN}_{1} \mathrm{~N}_{5} \mathrm{k}^{2}, \\
& \mathrm{~T}_{5}=\mathrm{k}^{2}-2 \mathrm{C} \omega^{2},
\end{aligned}
$$

$$
\begin{aligned}
& X_{1}=\left(1+N_{1}\right)\left(N_{3} k^{2}+2 N_{1}\right) k^{2}-N_{1}^{2} k^{2}, \\
& X_{2}=\left(1+C k^{2}\right)\left(N_{3} k^{2}+2 N_{1}\right)-N_{1} N_{5} k^{2} \\
& X_{3}=\frac{N_{2}}{P^{2}}+2 C X_{2},
\end{aligned}
$$

$$
\mathrm{A}=\frac{2 \mathrm{CN}_{2}}{\operatorname{Pr}} \mathrm{X}_{3}-\frac{2 \mathrm{CN}_{2} \mathrm{X}_{4}}{\operatorname{Pr}^{2}}
$$$$
\mathrm{B}=-\frac{2 \mathrm{CN}_{2}}{\operatorname{Pr}}\left(\mathrm{X}_{1}+\mathrm{k}^{2} \mathrm{~T}_{2}\right)-\mathrm{X}_{2} \mathrm{X}_{3}+\left(\frac{\mathrm{N}_{2} \mathrm{k}^{2}}{\mathrm{Pr}^{2}}+2 \mathrm{CX}_{1}+\mathrm{X}_{2}\right) \mathrm{T}_{4},
$$

and $\mathrm{E}=\mathrm{X}_{1} \mathrm{X}_{2}-\mathrm{k}^{2} \mathrm{X}_{1} \mathrm{~T}_{4}$

\section{Results and Discussions}

In this paper, we study the Rayleigh-Benard convection in Micropolar fluid by replacing the classical parabolic heat equation by a non-classical heat flux law. Figure (2) is the plot of critical $R_{c}$ versus Cattaneo number $C$ for different values of $N_{1}$. It is observed that as $N_{i}$ increases, $R_{c}$ also increases. Increase in $N_{1}$ indicates the increase in the concentration of microelements. These elements consume the greater part of the energy of the system in developing the gyrational velocities of the fluid and as a result onset of convection is delayed. From the figure (2) it is observed that $\mathrm{C}$ which represents second sound has a destabilising influence. The effects of $N_{3}, N_{5}$ and $C$ on $R_{c}$ are given in table (1). It is found that an increase in $\mathrm{N}_{3}$ is to destabilise the system while an increase in $\mathrm{N}_{5}$ is to stabilise the system. increase in $\mathrm{N}_{3}$, decreases the couple stress of the fluid which causes a decrease in microrotation and hence makes the system more unstable. When $\mathrm{N}_{5}$ increases, 
the heat induced into the fluid due to these microelements also increases, thus reducing the heat transfer from bottom to top. It is also found that $C$ has no influence on the critical wave number. For small values of $\mathrm{C}$, oscillatory convection sets in for heating from above and this is clearly shown in table (2).

Table 1 : Values of critical Rayleigh number $R_{c^{\prime}}$ critical wave number $a_{c}^{2}$ and critical frequency $\omega_{c}^{2}$ for different values of $N_{1}, N_{2}, N_{3}, N_{5}$, Pr and $C$ for a Micropolar fluid

\begin{tabular}{|c|c|c|c|c|c|c|c|c|}
\hline C & $N_{1}$ & $\mathbf{N}_{2}$ & $\mathbf{N}_{3}$ & $\mathbf{N}_{5}$ & Pr & $\mathbf{R}_{\mathrm{c}}$ & $a_{c}^{2}$ & $\omega_{c}^{2}$ \\
\hline $\begin{array}{l}0.1 \\
0.3 \\
0.5 \\
0.7 \\
0.9\end{array}$ & 0.1 & 0.1 & 2.0 & 1.0 & 10.0 & $\begin{array}{r}224.98 \\
73.58 \\
43.90 \\
31.27 \\
24.28 \\
\end{array}$ & $\begin{array}{r}10.08 \\
9.91 \\
9.94 \\
10.02 \\
10.14 \\
\end{array}$ & $\begin{array}{r}23.82 \\
12.60 \\
8.87 \\
6.58 \\
6.58 \\
\end{array}$ \\
\hline $\begin{array}{l}0.1 \\
0.3 \\
0.5 \\
0.7 \\
0.9 \\
\end{array}$ & 0.5 & 0.1 & 2.0 & 1.0 & 10.0 & $\begin{array}{r}350.94 \\
127.44 \\
76.21 \\
54.36 \\
42.24 \\
\end{array}$ & $\begin{array}{l}9.86 \\
9.90 \\
9.90 \\
9.74 \\
9.75 \\
\end{array}$ & $\begin{array}{r}10.62 \\
8.90 \\
6.04 \\
4.48 \\
3.60 \\
\end{array}$ \\
\hline $\begin{array}{l}0.1 \\
0.3 \\
0.5 \\
0.7 \\
0.9\end{array}$ & 0.1 & 0.5 & 2.0 & $1: 0$ & 10.0 & $\begin{array}{r}220.10 \\
72.11 \\
43.00 \\
30.61 \\
23.76 \\
\end{array}$ & $\begin{array}{r}9.95 \\
10.01 \\
10.27 \\
10.17 \\
9.98 \\
\end{array}$ & $\begin{array}{r}24.44 \\
14.11 \\
9.28 \\
6.80 \\
5.32\end{array}$ \\
\hline $\begin{array}{l}0.1 \\
0.3 \\
0.5 \\
0.7 \\
0.9 \\
\end{array}$ & 0.1 & 0.1 & 6.0 & 1.0 & 10.0 & $\begin{array}{r}217.53 \\
71.27 \\
42.51 \\
30.28 \\
23.50 \\
\end{array}$ & $\begin{array}{r}10.01 \\
9.89 \\
9.72 \\
9.64 \\
9.73 \\
\end{array}$ & $\begin{array}{l}25.17 \\
14.10 \\
9.08 \\
6.66 \\
4.82 \\
\end{array}$ \\
\hline $\begin{array}{l}0.1 \\
0.3 \\
0.5 \\
0.7 \\
0.9 \\
\end{array}$ & 0.1 & 0.1 & 2.0 & 1.5 & 10.0 & $\begin{array}{r}230.65 \\
75.61 \\
45.12 \\
32.14 \\
24.96 \\
\end{array}$ & $\begin{array}{r}10.07 \\
9.99 \\
9.86 \\
9.89 \\
9.88 \\
\end{array}$ & $\begin{array}{r}22.35 \\
13.19 \\
8.55 \\
6.33 \\
5.01 \\
\end{array}$ \\
\hline $\begin{array}{l}0.1 \\
0.3 \\
0.5 \\
0.7 \\
0.9\end{array}$ & 0.1 & 0.1 & 2.0 & 1.0 & 25.0 & $\begin{array}{r}226.61 \\
74.90 \\
44.81 \\
31.96 \\
24.84\end{array}$ & $\begin{array}{r}10.02 \\
10.19 \\
9.92 \\
10.44 \\
9.67\end{array}$ & $\begin{array}{r}22.88 \\
13.45 \\
8.62 \\
6.55 \\
4.97\end{array}$ \\
\hline
\end{tabular}


Table (2) : Values of critical Rayleigh number $R_{c^{\prime}}$ critical wave number $a_{c}^{2}$ and critical frequency $\omega_{c}^{2}$ for different values of $C$ and $N_{2}$ and for $N_{2}=0.1, N_{3}=2.0, N_{5}=1.0$ and $\operatorname{Pr}=10.0$ for a Micropolar fluid.

\begin{tabular}{|c|c|c|c|c|}
\hline $\mathbf{N}_{\mathbf{1}}$ & $\mathbf{C}$ & $\mathbf{R}_{\mathbf{c}}$ & $\mathbf{a}_{\mathrm{c}}^{2}$ & \multicolumn{1}{c|}{$\omega_{c}^{2}$} \\
\hline 0.1 & 0.002 & -6991127.00 & 512.22 & 64054990.00 \\
& 0.005 & -3137664.00 & 198.96 & 10251850.00 \\
& 0.007 & -1152220.00 & 139.28 & 5230719.00 \\
& 0.01 & -599794.40 & 94.53 & 2563493.00 \\
& 0.03 & -303159.60 & 24.92 & 285262.80 \\
& 0.05 & -20899.91 & 11.24 & 102869.90 \\
\hline 0.5 & 0.002 & -24516650.00 & 727.48 & 181326400.00 \\
& 0.005 & -4001038.00 & 284.87 & 28997100.00 \\
& 0.007 & -2068769.00 & 200.55 & 14787800.00 \\
& 0.01 & -1034842.00 & 137.33 & 7242847.00 \\
& 0.03 & -133721.10 & 38.97 & 801970.00 \\
& 0.05 & -57748.59 & 19.31 & 287757.20 \\
\hline
\end{tabular}

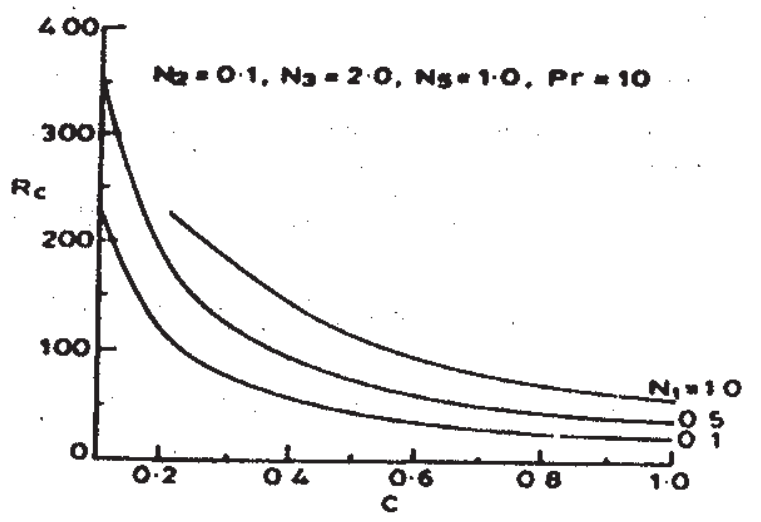

Fig 2 : Plot of Critical Rayleigh Number $R_{c} V_{s}$ Cattaned Number $C$ for Different Values of Coupling Parameter $\mathrm{N}_{1}$. 
Analysing equations (29) and (30) we can conclude the following for stationary convection in micropolar fluids:

$$
\mathrm{R}_{\mathrm{c}}^{\mathrm{HHE}}<\mathrm{R}_{\mathrm{c}}^{\mathrm{PHE}}
$$

where HHE - Hyperbolic heat equation and PHE - Parabolic heat equation.

\section{Conclusion}

The non-classical Maxwell-Cattaneo heat flux law involves a wave type heat transport and does not suffer from the physically unacceptable drawback of infinite heat propagation speed. The classical Fourier flux law overpredicts the critical Rayleigh number compared to that predicted by the non-classical law. Overstability is the preferred mode of convection.

\section{Acknowledgment}

The author would like to thank Dr. Pradeep G. Siddheshwar for suggesting the problem and for many stimulating discussions, and to the management and research development cell of Christ College for their support in completing this work.

\section{References}

1. Eringen A. C.: Simple microfluids with stretch. Int. J. Engg. Sci., 7, 115-127, (1969).

2. Eringen A. C.: Micropolar fluids with stretch. Int. J. Engg. Sei., 7, 115-127, (1986).

3. Eringen A. C.: Micropolar theory of liquid crystals. In: Johnson, J. F., Porter R. S. (Eds), Liquid crystals and ordered fluids, 3, Plenum Publishing Co., 1978.

4. Power H.: Bio-Fluid Mechanics, Advances in fluid mechanics, W.I.T. Press, UK, 3, 336, (1995).

5. Lukaszewicz: Micropolar fluid theory and applications, Birkhauser Boston, M. A., USA, 1998.

6. Eringen A. C.: Microcontinuum fluid theories, Springer Verlag, 1999.

7. Chandra K.: Instability of fluids heated from below. Proc. Roy. Soc. London A., 164, 231 242, (1938). 
8. Datta A. B., Sastry V. U. D.: Thermal instability of a horizontal layer of micropolar fluid heated from below. Int. J. Engg. Sci., 14, 631-637, (1976).

9. Bhattacharya S. P., Jena S. K.: Thermal instability of a horizontal layer of micropolar fluid with heat source. Int. J. Engg. Sci., 23, 13-26, (1984).

10. Payne L. E.:, Straughan B.: Critical Rayleigh number for oscillatory and non-linear convection in an isotropic thermomicropolar fluid. Int. J. Engg. Sci., 27, 827-836, (1989).

11. Siddheshwar P. G., Pranesh S.: Magnetoconvection in a micropolar fluid. Int. J. Engg. Sci., 36, 1173-1181, (1998).

12. Siddheshwar P. G., Pronesh S.: Effect of a non-uniform basic temperature gradient on Rayleigh-Benard convection in a micropolar fluid. Int. J. Engg. Sci., 36, 1183-1196. (1998).

13. Siddheshwar P. G., Pranesh S.: Effect of temperature / grovity modulation on the onset of magneto-convection in a weak electrically conducting fluids with intenal angular momentum. JMMM, 192, 159-176, (1999).

14. Siddheshwar P. G., Pranesh S.: Effect of temperature / gravity modulation on the onset of magneto-convection in an electrically conducting fluids with intenal angular momentum. JMMM, 219, L.153-L162. (2000).

15. Siddheshwar P. G., Pranesh S.: Effects of non-uniform temperature gradients and magnetic field on the onset of convection in fluids with suspended particles under microgrovity conditions, Indian Journal of Engineering and Mateials Sciences, 8, 77.83 (2001).

16. Siddheshwar P. G., Pranesh S.: Suction-Injection effects on the onset of Rayleigh-BenardMarangoni convection in a fluid with suspended particles, Acta Mechanica, 152, 241-252 (2001).

17. Siddheshwar P. G., Pranesh S.: Magnetoconvection in fluids with suspended particles under $\mathrm{lg}$ and $\mathrm{mg}$, International Journal of Aerospace Science and Technology, 6, 105-114 (2002).

18. Pranesh S.: Effects of Suction-Injection-Combination $(\mathrm{SIC})$ on the onset of Rayleigh-Benard magnetoconvection in a fluid with suspended particles, International Journal of Engineering Sciences, 41, 1741-1766 (2003).

19. Siddheshwar P. G., Pranesh S.: Linear and weakly non-linear analyses of convection in a micropolar fluid, Hydrodynamics Vl-Theory and applications Cheng \& Yeow (eds) 487 $493(2005)$.

20. Pronesh S.: Effects of magnetic field and non-uniform basic temperature gradient on the onset of Rayleigh-Benard convection in a micropolar fluid, MAPANA, 6, 1-33 (2007).

21. Straughan B, Franchi F.: Benard convection and the Cattaneo law of heat conduction. Proc. of Roy. Soc. of Edi. 96, 175 (1984).

22. Lebon G., Cloot A.: Benard-Marangoni instability in Maxwell-Cattaneo fluid, Phy. Let. 105A.361 (1984). 
23. Siddheshwor P. G.: Rayleigh-Benord convection in a magnetic field with second sound. Proc. Japan Soc. Mag. Fluids. 32, (1993).

24. Siddheshwar P. G., Rayleigh-Benard convection in a second order ferromagnetic fluid with second sound. Proc. Vill Asion cong., Fluid Mech. China 631, (1999).

25. Chandrasekhar S.: Hydrodynamic, Hydromagnetic Stability, Dover, New York, 1961. 